\title{
The relationship of transient hemiparesis following febrile convulsions in infancy to subsequent temporal lobectomy for intractable seizures
}

\author{
A DARKINS, CE POLKEY \\ From the Neurosurgical Unit, The Maudsley Hospital, London, UK
}

SUMMARY Nine patients with transient hemiparesis following a febrile convulsion were part of a group of 71 patients undergoing temporal lobectomy with mesial temporal sclerosis or nonspecific changes in the specimen. There was no gross evidence of additional brain damage in tests before surgery and their response to surgery was as good as the 62 patients without this history.

It is accepted that there is a relationship between prolonged febrile convulsions in infancy, the subsequent development of intractable temporal lobe epilepsy' ${ }^{1}$ and mesial temporal sclerosis, ${ }^{2}$ although Leviton and Cowan ${ }^{3}$ have questioned whether the relationship is strictly causal. In a small proportion of patients with this history the febrile convulsion is followed by a transient hemiparesis or hemiplegia of variable duration. Syndromes of hemiplegia in childhood have been variously described; important papers include a review by Ford and Schaffer, ${ }^{4}$ the classical paper describing the HemiconvulsionsHemiplegia-Epilepsy (HHE) syndrome, ${ }^{5}$ a review of the aetiological causes of acute hemiplegia in childhood, ${ }^{6}$ and more recent papers by Isler, ${ }^{7}$ and Solomon et al, ${ }^{8}$ who concluded that "seizures at the onset of hemiparesis heralded a poor prognosis for future seizures, hemiplegia, intellect and behaviour". It might therefore be expected that children who have had such a hemiparesis might be poorer candidates for subsequent surgery and we have set out to examine this suggestion both in relation to the evidence for brain damage in the preoperative tests and the results of surgery. It should be said that there was not a greater prevalence of such hemiparesis in patients rejected for surgery.

Address for reprint requests: Mr CE Polkey, Neurosurgical Unit, The Maudsley Hospital, De Crespigny Park, London SE5 8AZ, UK

Received 12 July 1984 and in revised form 14 October 1984 . Accepted 29 October 1984

\section{Clinical Material}

Seventy one patients who had undergone unilateral 'en bloc' temporal lobectomy for intractable seizures in the Neurosurgical Unit of the Maudsley Hospital between 1967 and 1983 were reviewed retrospectively. They were selected from a larger group of patients so treated, by the pathology found in the resected temporal lobe. In 62 of the 71 patients this was mesial temporal sclerosis and in the remaining nine patients non-specific changes were found. Full details of their postoperative course was available up to November 1983. Jensen's ${ }^{9}$ system of grading was applied to assess the relief of seizure after operation in the 53 patients who were followed for two years or more. The details of this grading system are shown in table 1 . All 71 patients were investigated in the usual way prior to temporal lobectomy. There was a detailed clinical history including seizure pattern and where possible the details were verified independently from other hospital notes. In addition virtually all patients underwent a detailed psychometric assessment, neurophysiological investigations which usually included sleep, pentothal activated sphenoidal EEG examinations, and radiological studies including a lumbar air encephalogram.

Nine of these 71 patients had a history of a transient hemiplegia following their febrile convulsion. In seven of these nine patients the side of the hemiparesis could be identified independently from hospital notes or doctor's letters. In the remaining two patients the hospital notes of one had been destroyed and in the other case the episode occurred in Cairo and no independent verification was possible. They were all aged between three months and $3^{1 / 2}$ years when this occurred. They had all been the product of full-term normal deliveries except one where forceps had been applied. They all passed their childhood milestones normally prior to the febrile convulsion. They would all satisfy the generally accepted criteria of "febrile convulsion" 10 and there was no evidence with that illness of primary brain infection. The possible causal agents to 
Table 1 Post-operative grading of patients

\begin{tabular}{ll}
\hline Grade & Post-operative seizure frequency \\
\hline GRADE 1 & $\begin{array}{l}\text { Five or less seizures in 5 years follow up or less } \\
\text { than one seizure per year }\end{array}$ \\
GRADE 2 & $\begin{array}{l}\text { A 75\% reduction on the seizure rate as compared } \\
\text { to that pre-operatively }\end{array}$ \\
GRADE 3 & $\begin{array}{l}\text { A 50\% reduction in the seizure rate as compared } \\
\text { to that pre-operatively }\end{array}$ \\
GRADE 4 & $\begin{array}{l}\text { A group that included some who were slightly } \\
\text { improved, those that remained the same and some } \\
\text { who were slightly worse }\end{array}$ \\
\hline
\end{tabular}

which the febrile event might relate are detailed in table 2 which also gives the mean age for the convulsion and the duration of the weakness where it is known. In most cases they lasted too long to be mere Todd's palsies. In six of the nine patients described the hemiparesis related to the same hemisphere as the temporal lobe which was subsequently removed (homolateral), and in the three others to the opposite hemisphere (contralateral). All nine patients had the lesion of mesial temporal sclerosis in the resected specimen. The 71 patients therefore were divided into three groups: those with no history of hemiparesis, (group A, 62 patients), those with a homolateral hemiparesis (group B, 6 patients), and those with a contralateral hemiparesis (group C, 3 patients). In groups $B$ and $C$ there was one patient with a family history of epilepsy and hemisphere dominance was known from the history in six cases and established by carotid amytal test in the remaining three. The other details of the patients in the three groups are given in table 3.

\section{Results}

A detailed consideration of the nine patients in groups $B$ and $C$ is of interest. They were all subject to frequent complex partial seizures. Their chronic seizures had appeared between eighteen months and thirteen years after the febrile event with a mean time of $8 \frac{1}{2}$ years. They were all subject to frequent complex partial seizures but in addition one patient had infrequent generalised seizures and another patient had frequent generalised seizures. They all failed to respond to adequate anticonvulsant treatment. Seven of these nine patients lived independent lives in the community with no evidence of behavioural disorder. One patient had been a

Table 2 Details of initial febrile illness

\begin{tabular}{lllll}
\hline Group & $\begin{array}{l}\text { Age at } \\
\text { hemiplegia }\end{array}$ & Causative agent & $\begin{array}{l}\text { Duration of } \\
\text { hemiplegia }\end{array}$ \\
\hline B & $1 \mathrm{yr} 5 \mathrm{~m}$ & $\begin{array}{l}\text { Measles } \\
\text { Herpes }\end{array}$ & 2 & 1 day to $1 \mathrm{~m}$ \\
(Homolateral) & & $\begin{array}{l}\text { Vaccination } \\
\text { Unknown }\end{array}$ & 2 & \\
& Strep & 1 & $24 \mathrm{~h}$ \\
C & $1 \mathrm{yr} 1 \mathrm{~m}$ & $\begin{array}{l}\text { Unknown } \\
\text { (Contralateral) }\end{array}$ & 2 & \\
\hline
\end{tabular}

hyperactive child and the other patient was subject to aggressive behaviour when on high doses of anticonvulsants. Six of the nine patients survived in the normal school system, two of these obtained A levels and one a degree. Two had been at special schools and one had not attended school for eighteen months because of fits and aggressive behaviour.

The premorbid hemispheric dominance was not known. At operation eight of the nine patients were left hemisphere dominant and this had been the affected hemisphere in seven of the nine cases.

The results of EEG investigations may be summarised as follows. Before operation all the patients in group B and in Group C had a unilateral focal abnormality in the temporal lobe on the side of the resection. All the patients in both groups had the normal post-resection changes in their EEG. One patient in group $C$ had changes in the post-resection EEG suggestive of diffuse damage on the side of the resection but suffered only infrequent fits.

The main results of the psychometric testing for each of the eight patients out of the nine who were tested in detail are in table 4. One of the six patients in group B had no focal abnormality on testing, four patients had evidence of damage to the temporal lobe which was subsequently resected and hence the hemisphere apparently affected by the insult in infancy. In the remaining case, where dominance had been confirmed by a carotid amytal test to relate to the side of resection, there was some bilateral damage with an appropriate verbal/performance deficit but also some non-dominant deficits. In group C one patient was not tested, one patient had a deficit related to the side of the resection but the other patient, who was ambidextrous, had damage corresponding to the side of the childhood insult. It is difficult to interpret these changes because we have found that in some patients with severe damage in one temporal lobe the spread of deficit on psychometric testing, usually when the insult has occurred early in life, suggests bilateral damage. however when carotid amytal tests are carried out on such patients it can be seen that the damage is clearly unilateral. In group B the temporal horn was dilated on the side of the resection and therefore childhood insult in all cases although one patient had bilateral dilatation. In group $\mathrm{C}$ the temporal lobe was dilated on the side of the resection in two cases but in one case there was dilatation of the opposite temporal horn. It has previously been shown that there may be dilatation of the temoral horn opposite to the side of the resection without any clinical or psychometric evidence of bilateral damage." The results of the surgery in relieving epilepsy are satisfactory as shown in table 5. When 
Table 3 Details of patients reviewed

\begin{tabular}{|c|c|c|c|c|c|c|c|}
\hline Group & $\begin{array}{l}\text { Sex } \\
\text { Male }\end{array}$ & Female & Age at operation & $\begin{array}{l}\text { Pathology } \\
\text { MTS }\end{array}$ & $N S$ & $\begin{array}{l}\text { Side of operation } \\
\text { Left }\end{array}$ & Right \\
\hline $\begin{array}{l}\mathbf{A} \\
\mathbf{B} \\
\mathbf{C}\end{array}$ & $\begin{array}{r}39 \\
1 \\
3\end{array}$ & $\begin{array}{r}23 \\
5 \\
0\end{array}$ & $\begin{array}{l}24 \\
27 \\
18\end{array}$ & $\begin{array}{r}53 \\
6 \\
3\end{array}$ & $\begin{array}{l}9 \\
0 \\
0\end{array}$ & $\begin{array}{r}34 \\
5 \\
1\end{array}$ & $\begin{array}{r}28 \\
1 \\
2\end{array}$ \\
\hline
\end{tabular}

MTS = mesial temporal sclerosis

NS $=$ non-specific changes

Table 4 Psychometric assessment of patients prior to operation

\begin{tabular}{|c|c|c|c|c|c|c|}
\hline Case No & Test & Verbal IQ & Performance IQ & $\begin{array}{l}\text { Additional } \\
\text { Sub-test Deficit }\end{array}$ & $\begin{array}{l}\text { Side of } \\
\text { Lobectomy }\end{array}$ & Cerebral Dominance \\
\hline $\begin{array}{l}\text { Group B } \\
1 \\
2 \\
3 \\
4 \\
5 \\
6\end{array}$ & $\begin{array}{l}\text { WAIS } \\
\text { S/WAIS } \\
\text { WAIS } \\
\text { WAIS } \\
\text { WAIS } \\
\text { S/WAIS }\end{array}$ & $\begin{array}{r}74 \\
133 \\
118 \\
114 \\
79 \\
111\end{array}$ & $\begin{array}{r}103 \\
103 \\
126 \\
96 \\
74 \\
100\end{array}$ & $\begin{array}{l}\text { Bilateral } \\
\text { None } \\
\text { Left } \\
\text { Left } \\
\text { Left } \\
\text { None }\end{array}$ & $\begin{array}{l}\text { Left } \\
\text { Right } \\
\text { Left } \\
\text { Left } \\
\text { Left } \\
\text { Left }\end{array}$ & $\begin{array}{l}\text { Right } \\
\text { Left } \\
\text { Left } \\
\text { Left } \\
\text { Left } \\
\text { Left }\end{array}$ \\
\hline $\begin{array}{l}\text { Group C } \\
1 \\
2 \\
3\end{array}$ & $\begin{array}{l}\text { S/WAIS } \\
\text { S/WAIS } \\
\text { This pat }\end{array}$ & $\begin{array}{c}102 \\
91 \\
\text { ot tested }\end{array}$ & $\begin{array}{l}106 \\
106\end{array}$ & $\begin{array}{l}\text { Left } \\
\text { Left }\end{array}$ & $\begin{array}{l}\text { Left } \\
\text { Right } \\
\text { Right }\end{array}$ & $\begin{array}{l}\text { Left } \\
\text { Left } \\
\text { Left }\end{array}$ \\
\hline
\end{tabular}

the 53 patients who have been followed-up for two years or more are reviewed then $58 \%$ fall into grade 1 with less than one fit per year of follow-up and a further $21 \%$ have a significant improvement in their epilepsy leaving a failure rate of $21 \%$. Among these 53 patients there are six who had a hemiparesis with their infantile febrile convulsion and four fall into grade 1 and two patients into grade 2 . The figures are obviously too small for formal statistics but it is clear that the patients who had the childhood hemiparesis have not faired any worse than those who were spared this complication.

\section{Discussion}

The patients in this study are highly selected and are not a representative population. In some cases the details of the cerebral insult in childhood are scanty and no angiography was carried out at the time. Yet they have certain common characteristics; the hemi-

Table 5 Relief of epilepsy in 53 patients with two or more years of follow-up

\begin{tabular}{llrrrrr}
\hline Group & & \multicolumn{5}{c}{ Grade } \\
& & \multicolumn{1}{c}{1} & 2 & 3 & 4 \\
\hline A & MTS & 40 & 26 & 7 & 3 & 4 \\
& NS & 7 & 1 & 2 & 1 & 3 \\
& Total & 47 & 27 & 9 & 4 & 7 \\
B & MTS & 4 & 3 & 1 & 0 & 0 \\
C & MTS & 2 & 1 & 1 & 0 & 0 \\
All & & 53 & 31 & 11 & 4 & 7 \\
\hline
\end{tabular}

plegia was preceded by an episode of status epilepticus in seven of the nine patients, all of the patients were less than $3 \frac{1 / 2}{2}$ years of age when the febrile convulsion occurred and they all subsequently developed chronic intractable seizures. They may therefore be considered as a subgroup of patients in the spectrum of childhood hemiplegias. Isler ${ }^{7}$ studied cases of childhood hemiplegia with angiography and isolated two clear groups, one in which a clear vascular cause was demonstrated and another, the larger, in which such a cause was not found. This larger group had in common the abrupt onset of hemiconvulsion associated with a febrile illness, without evidence of encephalitis, occurring almost exclusively in children under four years of age. He mentions the possible role of cerebral oedema, illustrating this with a case in which there was swelling of the affected hemisphere followed by later atrophy as demonstrated by serial pneumoencephalography. Aicardi et al ${ }^{12}$ reviewing 122 cases of acute hemiplegia in infancy and childhood, could divide them into a group of 69 in whom the hemiplegia followed status epilepticus and the remainder in who it did not. Many of the post-convulsive group were less than two years of age at the time of their insult, had been of low birth weight, and there was often a history of antecedent infection. Only one in six of these patients was mentally normal, and 58 of the 80 had chronic epilepsy the commonest form being complex partial seizures. In this group the cerebral angiograms when performed were always normal and in 
some cases pneumoencephalograms showed hemispherical atrophy which was acquired and preceded by transient swelling of the affected hemisphere. The study of Solomon et $^{\mathbf{l}^{8}} \mathrm{l}^{\mathbf{3}}$ describes eight groups, concentrating upon two of them. One described as "vascular occlusive" occurs mainly in children over two years of age without seizures, and another group in who no cause was found, the "unknown" group. This "unknown" group consisted of 25 children, mostly under two years of age who often had an unexplained fever at the onset of their illness; multiple seizures were present in 15 children and associated with a poor prognosis, four cases had only single or few seizures and in six cases there were no seizures at all.

Mises et $\boldsymbol{a l}^{13}$ describe the evolution of EEG spike foci in twelve out of fifteen children who had a transient hemiplegia following a unilateral seizure and thirteen of these children had no further seizures on follow-up whereas the remaining two children each had one further seizure. All except two of these fifteen children subsequently had normal intellectual development and in the two affected this was minor amounting to one year's delay in school.

The patients in this study have some features in common with the "non-vascular" group of Isler," the convulsive group of Aicardi' ${ }^{12}$ and the "unknown" group of Solomon. ${ }^{8}$ They differ however from these groups in one respect in that they have a much better chance of normal intellectual development and thus have something in common with the patients described by Mises. ${ }^{13}$ At the other extreme of this range are the patients with HHE syndrome. Thus we see a spectrum of residual epilepsy and brain damage from the patients with a benign EEG focus, ${ }^{13}$ through those described here in whom the permanent effects of their prolonged febrile convulsion were epilepsy and mesial temporal sclerosis, followed by those with more extensive brain damage,,$^{78^{12}}$ to the opposite extreme of those with HHE syndrome. The EEG evidence would to some extent corroborate this ranging from the benign spike foci of Mises, through the temporal spikes in mesial temporal sclerosis to the grossly abnormal records seen in the more extreme examples of hemispheric damage.

A pathological mechanism for these events can only be speculative on the available evidence. Perhaps the abnormal biochemical events in the immature brain, ${ }^{14}$ and precipitated by pyrexia may lead to neuronal swelling. The pneumoencephalographic observations of Isler and Aicardi suggest that this may be cortical resulting in hemispheric shift and resolving later with atrophy the area and degree of which would govern the extent of the final neurological deficit. Because the hippocampus tol- erates ischaemic poorly ${ }^{2}$ mesial temporal sclerosis may be the only permanent sequel whereas when the swelling recedes the motor cortex may recover. On the other hand, in the patients described by others, ${ }^{812}$ the neuronal swelling is more widespread and not fully reversible so that there are residual motor, behavioural and intellectual deficits as well as the seizures. The patients with the HHE syndrome $^{5}$ have clearly suffered the most severe and irreversible damage.

Temporal lobectomy for intractable temporal lobe epilepsy can be expected, in two-thirds of cases, virtually to abolish such attacks with a negligible mortality and few operative complications. ${ }^{9}$ There is no means of adapting such surgery to suit the patient; the operation is successful only if stringent criteria are met and the right patient is selected for surgery. The nine patients described in this study have differed from those usually considered for temporal lobectomy in that they had a history of a significant but transient childhood hemiphegia. Such patients might be thought logically to have sustained some diffuse damage outside the temporal lobe which would either make them unsuitable or poorer candidates for surgery. As already described, the pre-operative tests did not support this idea.

A knowledge of cerebral dominance is important in interpreting the results of the psychometric testing as well as in determining the extent of any subsequent temporal lobectomy. This had to be taken into account in assessing lateralised evidence of brain damage. The question of "hemispheric switching" is more complex than a simple response to injury. ${ }^{1516}$ In this group of patients we have no evidence about hemispheric dominance prior to the initial illness and therefore no knowledge of the effect of that illness upon it. However, in view of the fact that the left hemisphere was the one more often affected, and yet the normal distribution of dominance is seen in the patients at operation, we can speculate that hemispheric dominance has not been affected by the childhood illness.

We have already seen that in the six of these nine patients in which there is a long enough interval of follow-up the results of operation on seizure frequency are at least as good as those of the main body of patients in group A. Even in group $\mathrm{C}$ where the affected hemisphere as indicated by the childhood hemiparesis was opposite to the side of the resection, not only did the resected specimen contain the lesion of mesial temporal sclerosis but the result of surgery was equally good. We must therefore assume that any change produced by the childhood insult outside the temporal lobe was slight. A history of transient hemiparesis accompanying a febrile convulsion is not therefore a bar to temporal lobec- 
tomy provided the other criteria are satisfied.

The authors are grateful to many colleagues who have assisted in the management of these patients. Some of the temporal lobectomies were carried out by the senior author, the remainder by the late Murray Falconer.

\section{References}

' Ounstead C, Lindsay J, Norman R. Biological Factors in Temporal Lobe Epilepsy. Clinics in Developmental Medicine, 1966, No. 22. London SIMP with heinemann Medical.

${ }^{2}$ Falconer MA, Mesial Temporal (Ammon's Horn) Sclerosis as a common cause of epilepsy. Lancet 1974;2:767-70.

${ }^{3}$ Leviton A, Cowan L. Do Febrile Seizures Increase the Risk of Complex Partial Seizures? An Epidemiological Assessment. Febrile Seizures, Nelson KB, Ellenberg JH, eds, New York: Raven Press 1981;65-74.

${ }^{4}$ Ford FR, Schaffer AJ. The Etiology of Infantile Acquired Hemiplegia. Arch Neurol Psychiatry (Chicago) 1927;18:323-47.

${ }^{5}$ Gastaut H, Poirier F, Payan H, Salamon G, Toga M, Vigouroux M. HHE Syndrome: Hemiconvulsions, Hemiplegia, Epilepsy. Epilepsia 1960;1:418-47.

${ }^{6}$ Bickerstaff ER. Aetiology of Acute Hemiplegia in Childhood $\mathrm{Br}$ Med J 1964;2:82-7.
${ }^{7}$ Isler W. Acute Hemiplegia and Hemisyndromes in Childhood. Clinics in Developmental Medicine, 1971, Nos 41/42, London SIMP with Heinemann Medical.

${ }^{8}$ Solomon GE, Hilal SK, Gold AP, Carter S. Natural History of Acute Hemiplegia in Childhood. Brain 1970;93:107-20.

' Jensen I. Temporal Lobe Surgery Around the World. Results, Complications and Mortality. Acta Neurol Scand 1975;52:354-73.

${ }^{10}$ Millichap JG. The definition of Febrile Seizures. Febrile Seizures, Nelson KB, Ellenberg JH, eds, New York: Raven Press 1981;1-3.

"Newcombe RL, Shah. Radiological abnormalities in temporal lobe epilepsy with clinico-pathological correlations. J Neurol Neurosurg Psychiatry 1975;38:27987.

12 Aicardi J, Amsili J, Chevrie JJ. Acute hemiplegia in Infancy and Childhood. Dev Med Child Neurol 1969; 11: 162-73.

${ }^{13}$ Mises J, Plouin P, Bour F, Lerique-Keochlin A. A propos d'une d'epilepsie hemiconvulsive avec hemiplegie chex l'enfant. Rev EEG Neurophysiol 1981;11:445-9.

${ }^{14}$ Meldrum BS, Griffiths T, Evans MC. Epileptic Brain Damage. Rose FC ed Research Progress in Epilepsy, London. Pitman 1983;78-86.

is Wada JA, Clarke R, Hamm A. Cerebral hemispheric Assymmetry in Humans. Arch Neurol 1975;32:23946.

${ }^{16}$ Robinson RO. Equal Recovery in Child and Adult Brain. Dev Med Child Neurol 1981;23:379-83. 